\title{
Lighting education and outreach at Rose-Hulman Institute of Technology
}

Robert Bunch, Charles Joenathan

Robert M. Bunch, Charles Joenathan, "Lighting education and outreach at Rose-Hulman Institute of Technology," Proc. SPIE 10741, Optics Education and Outreach V, 1074102 (14 September 2018); doi: 10.1117/12.2319939

EDIE Event: SPIE Optical Engineering + Applications, 2018, San Diego, California, United States 


\title{
Lighting education and outreach at Rose-Hulman Institute of Technology
}

\author{
Robert M. Bunch* and Charles Joenathan \\ Rose-Hulman Institute of Technology, 5500 Wabash Ave., Terre Haute, IN, USA 47803
}

\begin{abstract}
The Department of Physics and Optical Engineering at Rose-Hulman Institute of Technology has served as an educational outreach partner with the National Science Foundation sponsored engineering research center, Lighting Enabled Systems \& Applications (formally Smart Lighting) for the past eight years. As part of the center, we developed educational materials on smart lighting, developed and taught lighting courses and workshops for both high school teachers and college students, and produced several short educational videos with students on lighting and general optical engineering topics. In this paper we will give examples of research and technical projects that were completed with students, discuss instructional materials that were developed, and describe the content of lighting and optics related educational videos.
\end{abstract}

Keywords: education, K-12 outreach, lighting, engineering

\section{INTRODUCTION}

Over the past several years, the lighting and illumination industry has undergone an unprecedented expansion beyond general house hold lighting with applications in communications, smart interior and exterior lighting systems, horticulture, health monitoring, and the automobile industry just to name a few [1]. This rapid advancement has been driven by new solid state lighting applications enabled by the development of high efficiency light emitting diodes, other high efficiency sources, and efficient detectors. With this expansion, the need for employees with an education and background in lighting, devices, and illumination, and related areas has also expanded [2-5].

Rose-Hulman Institute of Technology participated as one of the education, outreach, and research partners with the Lighting Enabled Systems \& Applications Center (LESA, formally Smart Lighting) for the past eight years. [6] Rensselaer Polytechnic Institute is the lead institution. Throughout our collaboration we have been involved in educational development and outreach. In educational development, we have organized summer research programs involving over 40 undergraduates and graduating senior high-school students. During the summer research program, the students conducted research and technical developments on projects related to lighting and optics. We also mentored directed research projects and capstone design projects, developed educational modules that were incorporated into Rose-Hulman courses [5], and developed a new elective course in the optical engineering degree program, OE434 Non-imaging Optics: Lighting and Illumination. In the area of outreach, we have facilitated K-12 outreach workshops, worked with students to develop educational videos on lighting and optical technologies, and performed community outreach. We also held one symposium involving the other LESA outreach institutions including, Howard University and Morgan State University. This paper summarizes our activities during our partnership with LESA. We hope that this will provide ideas and examples for other educators to use in their curriculum.

*bunch@rose-hulman.edu; phone 812 877-8306; fax 812 877-8023; www.rose-hulman.edu

Optics Education and Outreach V, edited by G. Groot Gregory, Proc. of SPIE Vol. 10741, 1074102

(C) 2018 SPIE · CCC code: $0277-786 X / 18 / \$ 18 \cdot$ doi: 10.1117/12.2319939 


\section{RESEARCH EXPERIENCES}

\subsection{Research Experiences for Undergraduates}

During each summer of our LESA partnership we provided a Research Experiences for Undergraduates (REU) program at Rose-Hulman. Besides Rose-Hulman undergraduate participants, we developed collaborations with Norfolk State University and Morgan State University to recruit students to participate in the REU program. In addition, during four summers, we included a high school student from the local area. The high school students are designated by LESA as Young Scholars, a high school student participating in a paid internship with LESA working on a LESA research project funded either by LESA direct funding or through an associated project.

The students worked on teams (two to three students) on a specific research project that we mentored and guided through an eight week summer period. A project title and a short description of the project was provided to each team on the first day of the program. Within the first week, the teams were required to conduct fundamental research on the topic, read relevant articles, and provide a list of equipment needed to conduct their research or project. By the beginning of the second week, the teams were required to submit a project plan (usually in the form of a Gantt chart) and give a presentation about their project to the mentors and the other teams. At the beginning of each week, each team was required to give a 15 minute oral presentation and submit a memo report about plans, activities to date, and goals for the next week. The summer program culminated in a final group presentation and a poster session.

Project examples included: "Solar energy harvesting for LED lighting", "Study properties of LEDs with temperature and current", "Environmental control of LED lighting", "Holographic optical elements for use in lighting", "Driving LED Light with Solar Panels", "Feasibility Study of Data Communication Using Visible Light Communication (VLC)", and "Color Detection and Color Temperature". One example research project was, "Study of white-light LEDs optical characteristics at high currents". This project involved driving an LED beyond its rated current and examining the effect of the spectral output all the way to LED component failure. The students developed a test bed for driving the LED and measuring the spectra and total output flux with increasing current. The detection system was comprised of a 12 inch integrating sphere (StellarNet IS12) and a StellarNet BLACK-Comet spectrometer. Figure 1 shows the spectrum of a white-light LED component for two different drive currents. As the current is increased within the range of the LED's rated forward current $(35 \mathrm{~mA})$, the output increases as expected. However, as current is increased beyond the rated forward current the output spectrum changes and the output flux decreases as shown in Fig. 2. The total flux output as a function of input current is shown in Fig. 3. Students recommended that the thermal properties of the LEDs should be measured simultaneously in a future project.

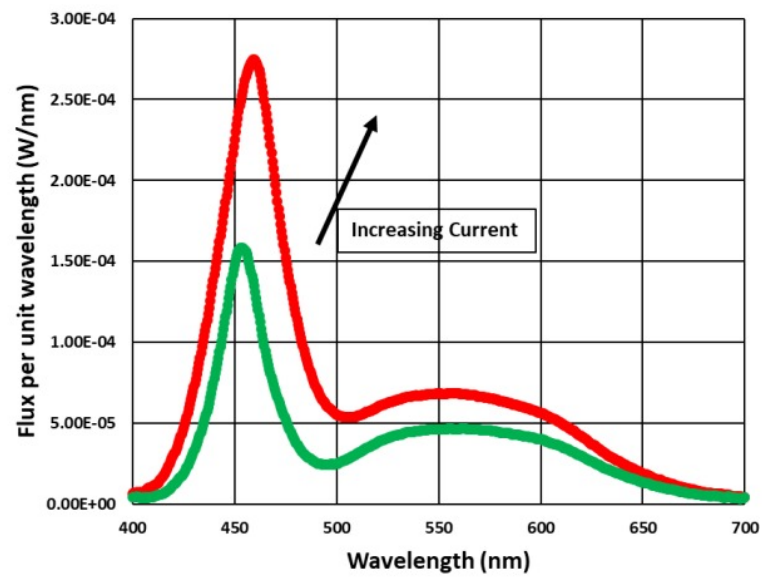

Figure 1. Spectra of white light LED for two currents below the rated forward current of $35 \mathrm{~mA}$. 


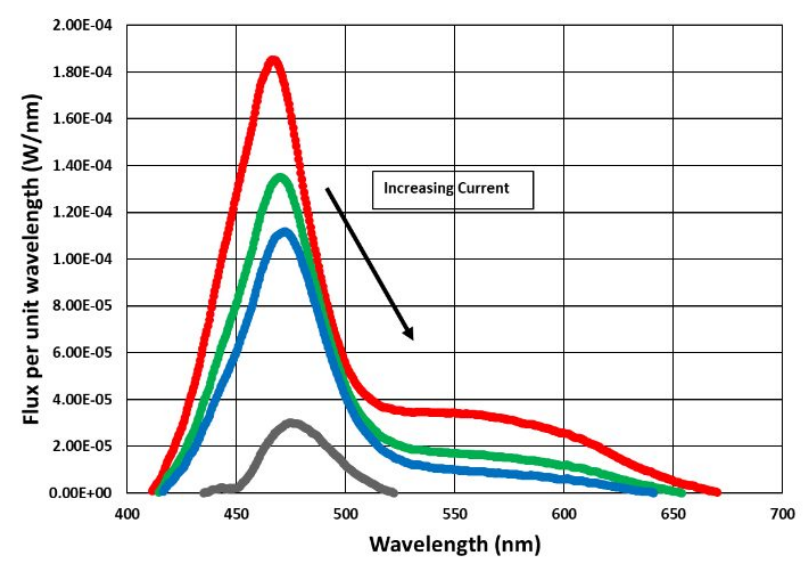

Figure 2. Four spectral scans of white light LED for drive currents of $82 \mathrm{~mA}, 95 \mathrm{~mA}, 115 \mathrm{~mA}$, and $125 \mathrm{~mA}$. The rated forward current is $35 \mathrm{~mA}$.

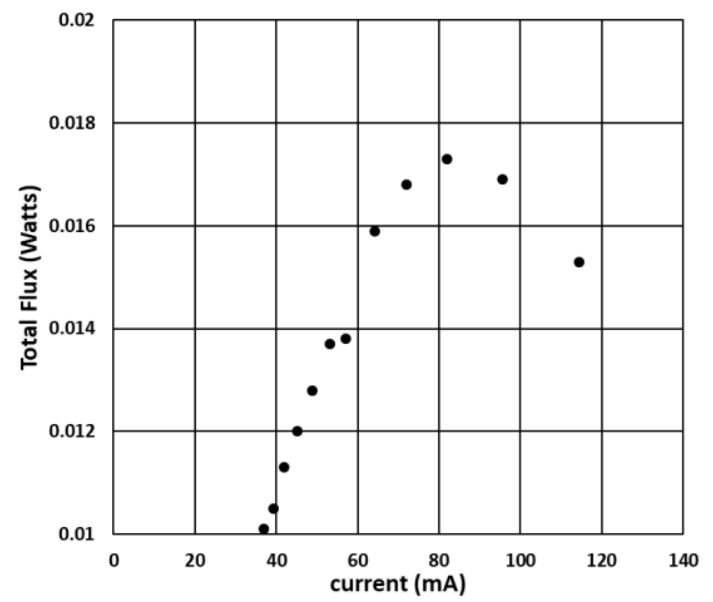

Figure 3. Total flux output from a white light LED as a function of drive current, up to and beyond the $35 \mathrm{~mA}$ rated forward current.

In addition to the research project each team was charged with producing an educational outreach video. More detail about these videos will be described later. We also incorporated a team building/creativity activity for all teams. One example was the development of a lighted sign for the student study area, they call the "h-bar". The students developed several concepts and with minimal faculty input chose a design for prototyping. The design for the display was inspired by REU research projects involving scattering of light in asymmetric waveguides and coupling of high brightness LEDs to structures. Figure 4 shows the lighted prototype display.

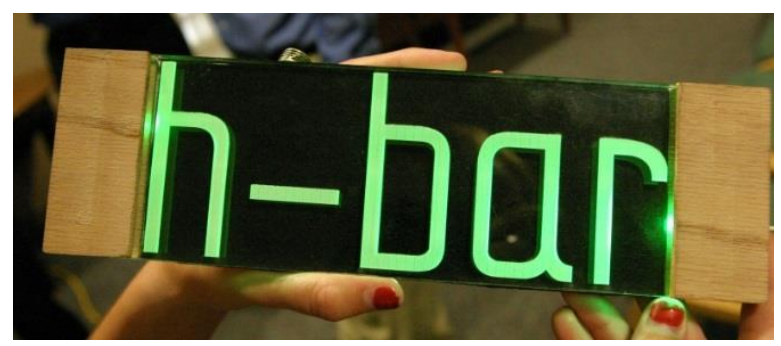

Figure 4. Prototype lighted display sign produced by a student group 


\subsection{High School Research and Mentoring}

Besides the Young Scholars program, we also partnered with Oak Lawn Community High School, Oak Lawn, Illinois (located in the Chicago Metropolitan area), through our connection and collaboration with a Rose-Hulman alum who is a science teacher at the school. His interest was mainly focused on providing a solid research experience for several of his students during the summer as part of a summer enrichment course.

The first suitable project chosen after several discussions with the high school teacher was to have the Oak Lawn group of students investigate a prototype LED light that was to be charged during the day with a solar panel and used for reading at night. This light source prototype was developed by an REU team sponsored by the Faculty without Borders group at Rose-Hulman to be implemented either in Kenya or Ghana. The high school students divided into teams to investigate a particular aspect of the development and testing resulting in studies on, "Battery Charge Time Field Test", "Optimal Power Field Study", and "Solar Panel Alignment Field Study". Their results were provided to the Faculty without Borders for further studies and expansion of the prototype. The students were mentored by the REU students through a skype meeting once a week. The work of the high school group was integrated with the REU projects at the end of summer poster session.

A second project example given to the high school group was to investigate the illumination pattern of various luminaires. As part of the research outreach, we donated two lighting kits to the school containing a white light LED as the main source, two reflectors, and three types of condensing optics along with the necessary optical power meters, lux meters, and individual detector components. For example, students were able to learn about illumination concepts and test the illumination level as a function of distance for each light configuration and compare the data to the ideal inverse square law. They also measured light profiles as viewed on an illuminated flat wall. The learning outcomes, set by their high school teacher in collaboration with the professors from Rose-Hulman, included defining experimental tests, collecting appropriate data, and fitting the data to a theory.

\section{OUTREACH}

\subsection{K-12 Teacher Workshops and Presentations}

One of the challenges associated with optics education is the pipeline of high school students interested in majoring in optical sciences and engineering. Consequently, we developed a work shop targeting high school science teachers so that they might gain some knowledge of optics and to make them aware of educational and professional opportunities for their students. A one-day workshop was organized with the goal to introduce the science and technology of modern solid state lighting and its applications including LEDs, basics of light, light measurement, light propagation, and color to secondary high school teachers. The workshop format included interactive lectures with group discussions, and hands on experiments using LED sources, lasers, and holograms. Each participant received materials to use in their classroom so that they can further develop age-appropriate activities that support and enhance the STEM (Science, Technology, Math and Engineering) curricula at their school.

Using our one-day workshop as a basis, we also ran several half-day workshops in partnership with Vigo County School Corporation (VCSC), and the Rose-Hulman supported program Portal Resource for Indiana Science and Mathematics (PRISM) for middle school teachers. [7] The program provides tools for teachers to integrate STEM concepts into their classroom instruction. The theme of their summer work is on energy conservation and lighting efficiency fit in well with the program. Workshop topics and activities included: Lighting History and Lighting Evolution, Understanding Light, Spectra, and LEDs, Light Measurements and Human Perception, Comparing Light Sources through Spectra. The major hands-on activity done by the teachers was to build their own holographic grating spectrograph.

In addition, several one-hour presentations were made on "Lighting, LEDs, and Energy Conservation" for selected high school teachers through the Duke Energy Sustainable Energy Institute on the Rose-Hulman Institute of Technology campus. The purpose of this institute is to provide the teachers a true "boot camp experience" in sustainable energies combining academic professional development on the Rose-Hulman campus with vocational experience through site visits to some alternative energy providers in Indiana. 


\subsection{Students-teaching-students: You-tube videos}

As mentioned previously, besides project work and research, each REU student team developed a video tutorial on some aspect of lighting, optics, and optical engineering associated with their project. The runtime of each video varied between 6-12 minutes. Examples of video tutorial topics include: "Light modulation and communication", "Solar cells", "PN junctions", "Radiometry and photometry terms and definitions", and "Light source characteristics". Some of the videos are available for viewing on the LESA youtube channel. [6,8]

\subsection{Community Outreach}

During two summers we had our REU student teams pool together and develop/modify an exhibit at the local Terre Haute Children's Museum as part of their team building experience. The museum staff was especially interested in ways to improve the quality of the appearance and lighting of one of their displays. The team visited the museum, observed how children interacted with various displays and proposed changes in one of the existing displays. The exhibit is entitled "Be and Architect". The student team recommended adding interactive and appealing elements such as: 1) Adjustment to make floor plans interchangeable, 2) Add multiple floor plans, 3) Improve attention and appeal, and 4) Make exhibit more interactive. The lighting of the floor plan was improved with LEDs embedded around the perimeter to index the interchangeable floor plans. Figure 5 shows an image of the completed display housed at the museum.

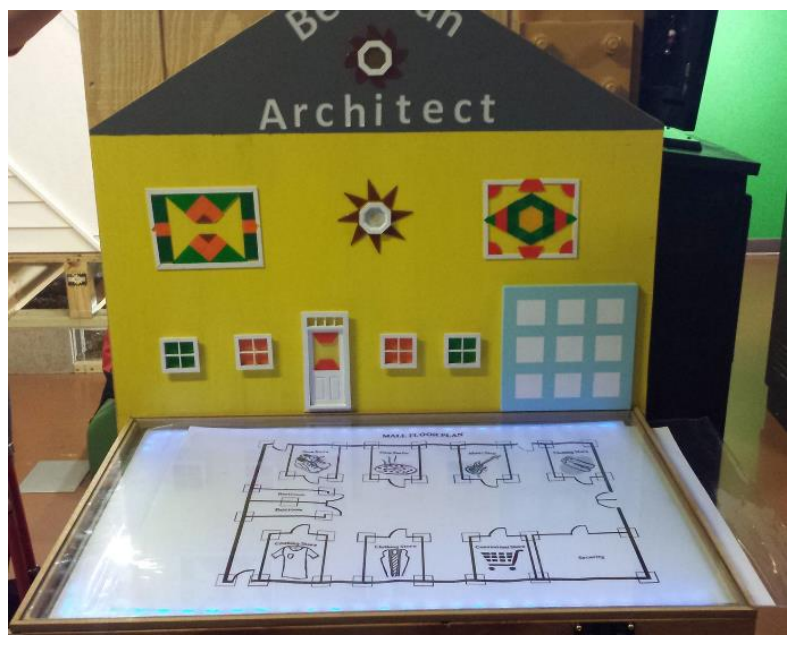

Figure 5. Photograph of the enhanced museum interactive display.

\section{LIGHTING AND NON-IMAGING OPTICS COURSE}

Over the past several years, more of our optical engineering majors were being employed by companies needing workers with a background in lighting and illumination. Employers encouraged us to provide more instruction in the fundamentals, design, and application of lighting and non-imaging optics. Our work on the development of modules with LESA provided us with the basic elements for an elective course for our optical engineering degree program. We piloted and then developed a new course OE434 Non-imaging Optics: Lighting and Illumination. The full course description as it appears in the Rose-Hulman course catalog is shown below.

OE 434 - NON-IMAGING OPTICS Credit Hours: 4R-OL-4C

Prerequisites: OE 295 - Photonic Devices \& Systems

Lighting, illumination, and solar concentration systems. Radiometry and photometry for illumination, etendue, and concentration. Color coordinates, color vision, and color measurements. Sources, light transfer components, and systems evaluation. Introduction to design methods (edgeray, compound parabolic concentrator, tailored reflector). Design examples and case studies. 
The course reviews and then builds on material that students have learned in the prerequisite OE295 Photonic Devices \& Systems where they first encounter radiometry and photometry principles, detectors, LEDs, and other optical sources. Topics of color, color vision, and color measurements are introduced. A large portion of the course involves design techniques important to non-imaging optical devices and systems.

Case studies are an integral part of the course and are chosen to focus on curiosity, innovation, and connection to lighting and non-imaging systems and how their design creates value for customers. The design components of the course are another natural way for students to make the connection between an engineering solution to a need and the value created in meeting this need. During the course, the students complete two major projects, one focused around lighting and lighting layouts and the other a specific luminaire design. As an example of a lighting layout design, Fig. 6 shows a student's design for a new hallway lighting system. The software design aid use in this case is the professional lighting design software program DIALux [9]

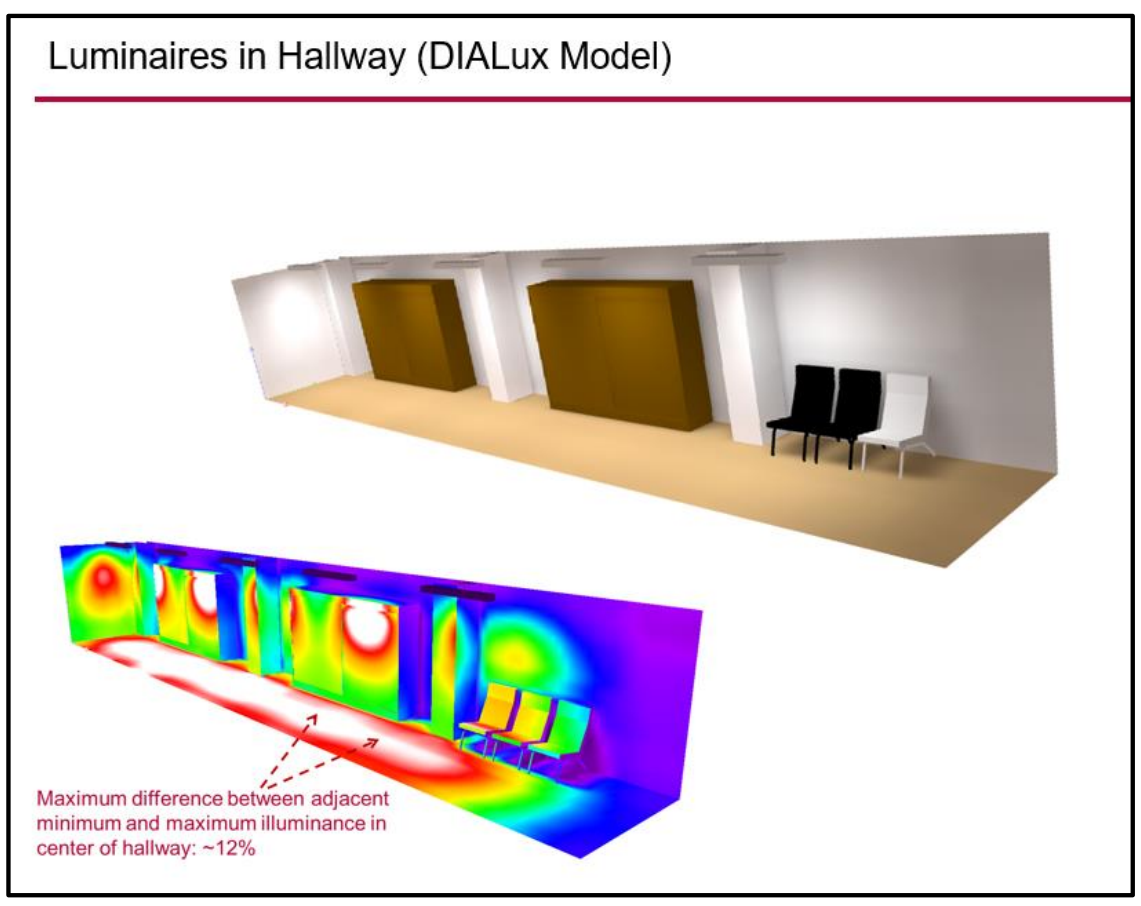

Figure 6 - Example of a page from a student's design report of a new hallway lighting arrangement showing a rendering from a DIALux model showing a rendering of the hallway and a pseudo-color map of the illumination levels predicted by the design.

The second major project is a luminaire design. The objective of this particular project was to design a reflector for landscape accent/ spot lighting and architectural lighting with homogeneous and well defined illumination between $\pm 40^{\circ}$. The source that was used to meet illumination specifications was a white planar LED, 30.95mm chip diameter, 2700 lumen output. The system was based on a single CPC reflector. Figure 7 shows student work from their design report at a step in the development process leading to a final design. The software LucidShape [10] was used to predict illumination uniformity. 


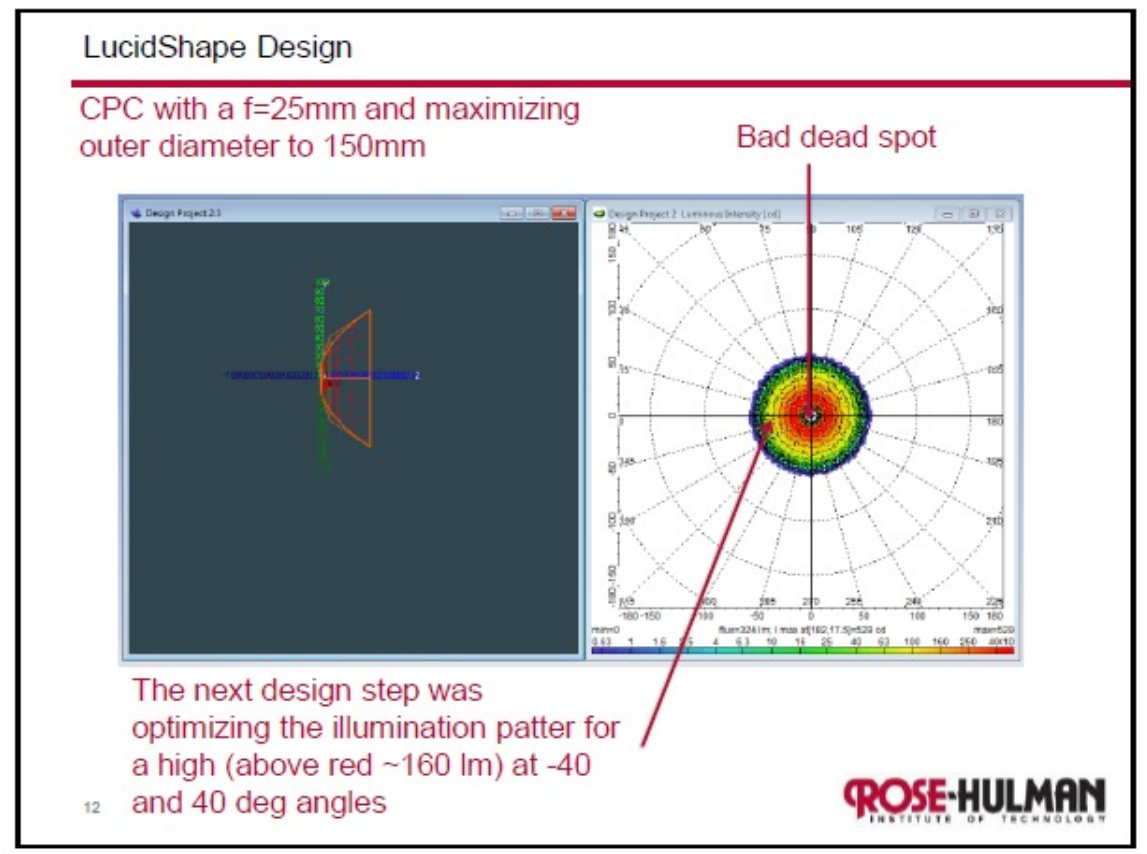

Figure 7 - Example of a page from a student's design report describing one of the interim steps in the design process of a luminaire and illustrating output from the optical design program LucidShape.

\section{SUMMARY AND CONCLUSIONS}

In summary, our educational outreach partnership with the National Science Foundation sponsored engineering research center, Lighting Enabled Systems \& Applications allowed us to increase awareness and importance of the multidisciplinary topics related to lighting and illumination to undergraduate students, high school students, high school teachers, and the community. We developed educational materials, taught lighting courses and outreach workshops based on these materials, and produced several short educational videos with students. Our undergraduate elective course has now been taken by over 20 Rose-Hulman undergraduate students providing them with an enriched background for work in the lighting industry. Our summer REU program included undergraduate students from Rose-Hulman, and HBCU schools such as Morgan State University, Howard University and Norfolk State University. We also involved four local high school students working along with the undergraduate researchers. Outreach activities to support K-12 education included having the REU students mentor a group of high school students working on mini-projects related to smart lighting and facilitating workshops for K-12 teachers.

High school students indicated that they would like to be made aware of the summer project earlier than the start of the summer so that they could get started as soon as the summer session begins. The undergraduate students liked the challenge of mentoring the high school students but facilitating frequent communication between high school students and student mentors is essential. Picking an appropriate project, outlining project scope, and defining educational outcomes is critical to success.

Teachers in each workshop indicated that they liked the hands-on activities, the diversity of activities, and interaction between the faculty and undergraduate student assistants. They especially appreciated receiving teaching materials that can be readily used in our classroom and laboratory to excite students. To improve the workshop teachers asked for more time to develop lab/lesson plans for their schools that could be shared with other teachers. 


\section{ACKNOWLEDGEMENTS}

This work was supported primarily by the Engineering Research Centers Program of the National Science Foundation under NSF Cooperative Agreement No. EEC-0812056. We also thank Mr. Chris Repa, Oak Lawn Community High School, Oak Lawn, Illinois, for his commitment to provide research experiences for his students. We would also like to thank Synopsys for providing a marketing loan for educational use of CODE V, LightTools and LucidShape

\section{REFERENCES}

[1] LED: A history of the future of lighting by Bob Johnstone. ISBN 9781546737421, 2017

[2] Julian, Warren G., "The Need for Lighting Education,” Proc. SPIE Vol. 4588, 155-162 (2002).

[3] Ronen, Ram S. and Smith, R. Frank, "Shedding Light on the Subject: Introduction to Illumination Engineering and Design for Multi-Discipline Engineering Students," Proc. SPIE Vol. 2525, 628-634 (1995).

[4] Koshel, R. J. et. al., "Illumination system design in a project-based course," Proc. SPIE 7423, 742305 (2009).

[5] Bunch, Robert M., Joenathan, Charles, Connor, Kenneth, and Chouikha, Mohamed "Modules to enhance smart lighting education" Proc. SPIE 8481, Optics Education and Outreach II, 84810B (October 15, 2012)

[6] https://lesa.rpi.edu/

[7] Carlson, Patricia, et.al, "Work in Progress: Merging Science Inquiry and Engineering Design: A Summer Workshop Series for Middle and High School Science Teachers," Proceedings, ASEE/IEEE Frontiers in Education. T1A-1-2. Rapid City, SD.

[8] http://www.youtube.com/results?search query=rose-hulman+smart+lighting

[9] https://www.dial.de/en/home/

[10] https://www.synopsys.com/optical-solutions.html 